\title{
The Virtual Organization from the Viewpoint of Informing
}

\author{
Vojko Potocan \\ Faculty of Economics and Business, \\ Maribor, Slovenia
}

Vojko.potocan@uni-mb.si

\author{
Marina Dabic \\ Faculty of Mechanical Engineeering, \\ Slavonski Brod, Croatia
}

\begin{abstract}
The conditions of globalization require companies to transform from the traditional industrial enterprises into the modern post-industrial ones, which are becoming open, flexible and innovative. The focus on knowledge has lead to increase attention towards information technology (IT) as one of the main source of competitive advantages. Organizational starting points for their functioning lead to a specific organizational structure, e.g. virtual organization. Virtual organizations enable organizational and/or individual core competencies to be brought together when needed, and disbanded when no longer required on one hand. On the other hand, competitive pressure over the modern conditions of business requires a high quality of business functioning. Business functioning of virtual organizations can be significantly improved mainly in the field of its management, which is its least developed and investigated area. An important viewpoint of management presents a holistic information support to management, which, to a great extent, determines the quality of the entire management and has also a major impact on the results of business operation.
\end{abstract}

Key words: virtual organization, information support, requisite holism of information support.

\section{The Selected Problem and Viewpoint of this Contribution}

The hyper competitive global economy has created a new competitive landscape - one in which events change constantly and unpredictably (Ireland, Hitt, 1997). Trends that appeared together with the development and the increasing application of information technology, whose influence on the organization structure is the greatest, are the business globalization, change in the structure of employees, elimination of boundaries among the parts within the organizations, but also among individual organizations.

Many organizations are forming strategic relationships in order to compete effectively (Porter, 1990). Many of these strategic relationships are conceived as a means to increase both the efficiency and effectiveness of those involved in these strategic relationships (Williamson, 1991; Gundlach, Achool, and Mentzer, 1995). Inter-organizational relationships have become one of the most frequently used means of entering or expanding in the global marketplace (Varadarajin, Cunningham, 1995). The virtual organization concept is a specific case of such relationships.

Material published as part of these proceedings, either on-line or in print, is copyrighted by Informing Science. Permission to make digital or paper copy of part or all of these works for personal or classroom use is granted without fee provided that the copies are not made or distributed for profit or commercial advantage AND that copies 1) bear this notice in full and 2) give the full citation on the first page. It is permissible to abstract these works so long as credit is given. To copy in all other cases or to republish or to post on a server or to redistribute to lists requires specific permission from the publisher at pubtistrem@intommingscience.org

\section{Business Operation and the Requisite Holism of Information}

Competitive pressure over the businesses, in the globalizing world economy, requires a high quality business operation (Porter, 1985). Business operation of enterprises can be significantly improved mainly in the field of its management, which is its 
least developed and investigated area (Potocan, 1997; Fry, Stoner, 2000). An important viewpoint of management is presented by the information support of management, which, to a great extent, determines the quality of the entire management and has also a major impact on the results of business operation (Potocan, 1997; Dabic, 2000; Potocan, 2001).

The main field of the business presents the economics-oriented operations, which is based on various sorts and types of information (quantitative, qualitative) (Schultheis, Sumner, 1998; Laudon, Laudon, 1998; Fry, Stoner, 2000). For the adequate running of the business operation we, namely, all the requisite (system of) various information with which quantity, value and quality (or any other important) characteristics of operations are presented. However, their treatment is linked to the variety of content and methodology issues (Brittan, 1997; Gunton, 1998; Fry, Stoner, 2000). However, their treatment is linked to a number of various issues concerning both its content and methodology. Holism of the treatment can best be attained, if a dialectical rather than a total systems of viewpoints is applied, but not so with a single viewpoint (Modis, 1998; Mulej et al, 2000, and earlier, since 1974).

The research about and the development of the information support to business operation involves the development of (1) a (requisitely) holistic (Mulej, Kajzer, 1998; Rebernik, Mulej, 2000) methodology of information support, and (2) creation of (requisitely) holistic implementation of information support. The created system of processes of information support to business also determines the starting points for a possible realization of the theoretical starting points in related sciences (economics, business) to considerably support the business. The information based on business sciences can be mainly acquired through a complex methodology, which is especially true in the case of their systemic (requisitely holistic) treatment.

If the Mulej/Kajzer law of requisite holism is well considered, the approach to and process of making and using the system of information provide support to business (Mulej, Kajzer, 1998). A lack of consideration of the Mulej/Kajzer law of requisite holism may rather easily show up, if the decision makers and their support offices / assistants try to limit their efforts to a single viewpoint and/or to hard-systemic data alone, such as accountancy or over-quantified marketing research data. They should better use a soft systems approach, too, and hence link different data and judgments (see: Checkland, Holwell, 1998).

This statement may be well know, in general, but there may be still an open issue of how can the requisite holism of information be attained in the virtual organizations. We shall, therefore, focus on the discussion of some issues concerning the virtual organization concepts, general virtual organization models about an enterprise, some characteristics of information support to virtual organizations from the viewpoints of the soft systems thinking, information support, and the law of requisite holism, as a dialectical system.

\section{The Virtual Organization Concept}

A distinguishing feature of the $21^{\text {st }}$ century is the prevalence and pervasiveness of different types and forms of networks, whether digital, social or organizational. The term "network", both a noun and a verb, is one of the most widely used words in our everyday vocabulary.

A virtual organization is "a collection of business units in which people and work processes from the business units interact intensively in order to perform work which benefits all" (Porter, 1990). Although virtual organizations have become a relatively widespread business approach to structuring business, the underlying concepts of linking competencies across business units or organizations have existed for some time earlier, too. These business linkages enable organizations to more tightly coordinate the transactions and activities across a value chain. Virtual reality, virtual space, virtual organizations, virtual teams; "virtual" is today's organizational buzzword (Johansson, 1995; Potocan, 2001). 
Virtual organizations enable organizational and/or individual core competencies to be brought together when needed, and disbanded when no longer required. These new firms mirror the fluidity of the global markets, creating, and disbanding resources as dictated by the marketplace. Global location, technical, workforce and market expertise advantages can be heightened through the use of the virtual organizational structure (Davidow, Malone, 1993).

The rationale for forming a virtual organization varies for the different entities involved in each relationship (Speier, Harvey, and Palmer, 1998; Harvey, Speier, and Novicevic, 2000; Harvey, Dabic, 2001). This desire to excel in a market characterized by hyper competition has motivated a growing number of organizations and individuals to search for uncommon associations to help develop creative and perhaps more effective strategies. Virtual organizations are able to generate new products more quickly, decrease the risk of pursuing a new opportunity, increase the visible organizational size, and decrease cycle times by relying on synergies of the core competencies of all their membership (Black, Edwards, 2000). Characteristics of virtual organizations are continuing to evolve. However, some characteristics that have been identified include (Porter, 1985; Porter, 1990): 1) A web of companies each contributing resources, 2) Virtually vertically integrated, 3) Linked through inter-enterprise business and production systems, 4) Aimed at reduced business cycle time, and 5) Aimed at one-stop shopping.

It would appear that creating a virtual organization to generate a product or service more effectively could include these two forms:

- Removing inefficient transaction costs from the value chain, such as reducing time to market; and

- Adding value to existing activities in the value chain enhancing the overall value of the product or service.

The tactical and operational activities are left to member units, at least in the models we detected (Harvey, Dabic, 2001).

\section{Virtual Global Organizational Models}

Virtual global strategic organizations involve inter-organizational relationships that exist in a variety of forms. These relationships can be based on existing relationships between firms and often reflect prior competitive or cooperative interactions (Hill, Hitt, and Hoskisson, 1992; Allcorn, 1997). In addition to these inter-organizational strategic relationships, firms must have an economic incentive for participation. Strategic needs, desire for performance enhancements, or an attempt to foster innovation can drive these incentives. Nike, e.g., was one of the first organizations that took advantage of advanced communication and logistic technology to create a global network of organizations to produce athletic shoes instead of keeping all the work inside the organization (Snow, Miles, and Coleman, 1992; Potocan, 1997; Harvey, Dabic, 2001)

Five identifiable models of virtual global strategic organizations begin to emerge from the existing literature (see: Porter, 1990; Davidow, Malone, 1993; Rayport, Sviokla, 1995; Allcorn, 1997). These models share common elements of coordination through the use of IT and communication technologies, and the performance of work across time and space (Speier, Harvey, and Palmer, 1998; Harvey, Speier, and Novicevic, 2000; Harvey, Dabic, 2001).

\section{Model I: Shared Partnership}

This shared partnership requires a compatibility of partner goals and values (Dess et al., 1995) and evolves from existing relationships that are strong between partnering organizations. Shared Partnership are no longer confined to firms in similar or related industries, but are increasingly formed across sectors that 
hitherto appear to be unrelated. A recent example includes Microsoft's alliance with Lego, the Danish toy manufacturer. To facilitate this trend toward global strategic alliances, new organizational forms and structures have been proposed. These include the concept of "boundaryless" organizations propounded by Jack Welch at General Electric and the "pizza chart" organization at Eastman Chemical. This model is often found in co-located, spin-off situations, where multiple firms share resources to develop new products or processes, working in close coordination. The shared partnership model is e.g. evident in the coalescing of expertise and sharing of risks among IBM, Sun, and Hewlett Packard on the development of the Internet programming language JAVA.

\section{Model II: Core/Satellite}

The second model reflects a core global organization maintaining relationships with satellite strategic organizations. The core global organization calls on advertising agencies, wholesalers, retailers and the like, from a variety of organizations to respond more effectively to market opportunities (Harrigan, 1988; Anderson, Narus, 1990). In many cases these are organizations based around similar industries located in different countries, each providing a strategic competency or expertise. The core satellite model is evident in the Chraysler/Daimler Benz and Pliva biotechnology Company. In this model, a core firm provides the impetus to form the global network of organizations (Snow, Miles, and Coleman, 1992) and this firm typically defines the work synchronicity, calling on satellite firm strategic capabilities as needed.

\section{Model III: Virtual Value Chain}

The next three models are based on the value or global supply chain model. The first of the three is a coordinated set of transactions among companies serving an end customer in a number of different countries with information technology supporting the development of the end product or service (IBM). This model is utilized on both a project basis, as in large construction projects in developing countries, and on a more permanent basis, such as in the case of Wal-Mart and international suppliers (Ring, Van De Ven, 1992). Benetton the Italian sportswear marketer is another example of this model.

\section{Model IV: Integrated Firm}

The fourth model takes a more integrated view of the global supply chain. This vertical integration results in autonomous units utilizing technology to coordinate efforts between functions and countries at the same time. A group of companies conduct related businesses as parts of a vertical set of processes to produce a good or service. This concept incorporates a continuing set of global strategic relationships (Anderson, Hakasson, and Johnson, 1994). This model is part of theory of the Firm as a Nexus of Contracts. Example of this model is BASF. BASF is taking part in a number of newly-announced e-marketplaces, which has established by Bayer Down Chemical, DuPont and Ticona.

\section{Model V: Electronic Market}

Within a very short period of time, e-commerce has accelerated the pace of commercial transactions across international boundaries much faster than decades, perhaps even centuries, of development in that arena. The establishment of an electronic market (Bakos, 1991) allows firms to compete n global markets while allowing customers to select from a variety of potential providers. In this model the technology itself serving as a key component in creating the market among the virtual global strategic organizational partners. In some cases, the electronic market is open and other strategic relationship members serve as intermediaries. An example of an open market is the wine market and digital newspapers on the World Wide Web, with multiple vendors competing for worldwide business (Rayport, Sviokla, 1995). Examples 
include amazon.com connecting with book dealers. This model is also evident on example of Royal Bank of Scotland (Oates, 1998).

We can conclude that all five models address the basic process, first of all, or even exclusively. The management and the information processes are left aside, obviously. In reality, as visualized by business cybernetics (Kajzer, Mulej, 1999; Checkland, Holwell, 1998), this is a case of a crucial lack of requisite holism. That's why we will add the information viewpoint, on the level of a first discussion.

\section{Information Support to Virtual Organization in the Perspectives of the Soft Systems Theories}

Due to the above conclusion, we deal with the business operation of virtual organization from the information as a part of the objective starting points (possibilities/sources) rather than need which are meet with them. Information represents important (=requisitely holistically presented) characteristics of the examined field and the requisite additional knowledge (from the content and methodological aspects) (see: Laudon, Laudon, 1998; Becker, Kugeler, and Rosemann, 2000). The development of the information support to organization operation enables the acquisition of both non-economic and general economic information as a picture/model of business operation from the (dialectical system of) selected viewpoints (Borghoff, Pareschi, 1998; Flood, 1999; Mulej et al., 2000).

The business operation can be considered adequate when it takes place successfully (efficiently and effectively in economic terms), is respected (from the aspect of business behavior) and ethical (morally adequate from the aspect of a responsible attitude towards the social and natural environment) (Gunton, 1998; Flood, 1999). The business operation needs different kinds of information that can broadly be defined as general information (Potocan, 1997; Dabic, 2000; Potocan, 2001). The majority of general information can also have a direct or indirect impact on the economics of business. For this reason, the information business related - can be also defined as economic information in the broadest sense of the word. In the business treatment, we can also encounter a group of information that can be defined as non-economic information (complementary to the economic information in the work process). These are the messages, data or information that are indirectly related to the business or are not included (and/or are not applied) in the treatment of business, such as sociology, psychology, communication, technology development, low, languages, etc.

The problem of the theory and practice of business informatics, since its beginning, has lied in its target orientation to ensure the directly economic/business information (Gunton, 1998; Lucey, 1998; Becker, Kugeler, and Rosemann, 2000; Fry, Stoner, 2000). Information support has been very often limited only to the financial aspect of the economic/business operation. Financial information presents, nevertheless, an important subsystem of information and is, at the same time, rarely a partial system of a needed entire information support to business operation. The focus of the modern business information is in providing most of the information necessary for the business operation. Herein, the increased importance of another subsystem of information, which is not only economical from the content aspect, has however an important (indirect or direct) impact on the economics of business. Owing to its significance and impact on the economics of business, we have defined this information as the (direct) economics information. The noneconomic information is complementary to it; they meet the Law of the requisite holism together.

The treatment of the indirect economic information is difficult and is additionally made more difficult by the problems of its definition (Potocan, Kajzer, and Mulej, 1997; Potocan, 2001). At the level of its content definition, the information can be defined as objective and subjective. The objective information is the information that can be rather well defined and, therefore, well investigated on the basis of different quantity units (i.e.: quantity, weight, value). On the other hand, we have subjective information that is less unified a less 
clearly defined. The subjective information is, as a rule, examined by the application of various quality units or even only by the application of descriptive criteria. Objective and subjective messages, data, and information) require interpretation, which tends to be quite subjective, because it is done by humans. However, we have not yet exhausted the problems how to define the objectivity and subjectivity of information, which can be dealt with further on the basis of the needs and the definition of the requisite objectivity. In the literature to which we have access, we miss investigations that thoroughly study the issues of the subjective information and/or the subjectivity of the information definition.

A needed information structure for doing the business presents an additional problem as concerns the treatment of the business information support (Potocan, Kajzer, and Mulej, 1997). In this, we encounter two aspects of the structure suitability, i.e.: an adequately target oriented information, and a suitable level of unification of information. For the needs of the individual business (different kind, type and form) and business operations in the individual areas of industries and markets, we need the information that is suitably conceived and created in accordance with the set goals. On the other hand, we need different general and specific information for each business operation.

If we want to define the information support of business operations, we must first define the level of research, creation and application of information support. The Law of requisite holism presents one possible solution for that.

\section{Information Support and Law of Requisite Holism}

A central question in the creation of information support to business lies in the definition of its basic characteristics (how do we define the level of its holism, variety, effectiveness, efficiency, entanglement, simplicity, unification, standardization, originality) (Potocan, 1997; Potocan, Kajzer, and Mulej, 1997; Merry, 1999; Merry, 2000). It all depends on our selection of the individual viewpoint / dialectical system / viewpoints system / total system of viewpoints (Mulej et al., 2000; Potocan, 2001).

In the treatment of business phenomena, we are additionally encountering the problems of how to define a requisite information support to business operation (Potocan, Kajzer, and Mulej, 1997; Mulej et al., 2000). A necessary support to our consideration can be defined as the state of consideration of the phenomenon that enables us to create a requisitely holistic insight into the phenomenon and a requisitely good quality of treatment of business. On the other hand, the requisitely support can be defined as the state of the insight in the phenomenon, which enables us to requisitely usefully create the picture of the phenomenon in accordance with the starting points of the treatment. Holism can be delimited likewise. The sufficient level of holism is, therefore, frequently lower than the necessary one (Kajzer, Mulej, 1999; Mulej et al., 2000), they make the requisitely level together, mostly, anyway.

The above findings, additionally confirm the fact that the examination of business operation is very demanding. This especially applies to the information support of business operation. An appropriate level of information support of business operation can be defined according to the law of the requisite holism. We apply this law to the treatment of entanglement of information support.

The Law of the requisite holism was formulated by Mulej and Kajzer in 1998 (Mulej, Kajzer, 1998; Kajzer, Mulej, 1999; Mulej et al., 2000). It is defined at least by the following characteristics. The entanglement of the nature has constantly been increasing. The development of the complexity of life is thus quicker than the one of the human abilities to understand and manage it holistically (Kajzer, Mulej, 1999; see: Flood, 1999). Humankind has been strengthening many narrow specializations and is, therefore, restricted to the individually selected aspects and to the individually selected phenomena. The systems theory endeavors to assert the holism of the examined reality, of the life and its component parts. Each au- 
thor, within the definition of his/her starting points for the treatment, defines what is seen as a requisite holism in his / her case.

The Mulej/Kajzer law expresses the difficulties, which are results of the entangled reality. Within an enhanced, deeper investigation we can see that it makes sense to study the entanglement concepts in more detail in order not to miss something very important. On the base of mentioned cognitions we research selected starting points of the economic examination of business. The Mulej/Kajzer law of the requisite holism applies to the comprehensiveness of thinking, decision-making, and action.

On the other hand, the Ashby's Law of requisite variety (see: Ashby, 1973) mainly advocates the fact that each unit / entity / system must, after its appearance, care for the maintenance (and an appropriate development) of its identity in order to have (in an ideal case) an adequate response prepared in advance for each and every important impact from the environment, threatening its identity.

The requisite holism of the information support may best be attained if both the Mulej/Kajzer and the Ashby laws are considered. This applies to both the traditional and the virtual organization, but may be a lot more complex and complicated in the case of the virtual one, because its legal and management frame works is more fluid.

\section{Concluding Remarks}

Assessing and implementing of virtual organizational models and virtual management provides an organization a template for increasing the control and viability of its global operations. Each virtual model is likely to require its own greater emphasis to certain facets of the virtual management process and less emphasis on others. This emphasis will be related to the degree to which the given relationships exist in the power distribution (e.g., shared partnership vs. core/ satellite) between organizational partners, and much more.

In the circumstances of restricted available factors and present conditions of business operation, results can be primarily improved by an adequate management. Various solutions are available to improve the quality of management while one important improvement of business is provided by a suitable information support of business, its management and basic processes.

In business systems the management is mostly oriented to the economics of operation. Also, a corresponding economics orientation of business should be provided in the formation and application of the business system. The business process is based upon the information basis with which we represent important characteristics of the examined field and the requisite additional knowledge (from the content and methodological aspect).

The requisite information is formed in the processes of business operation and accounting etc. support to business. The development of the information support to business activities enables the creation / acquisition of the non-economic and general economic information on the picture of business operation. However, for a successful implementation of the business, additional and specifically structured economic information is needed. The information is formed in the requisite target (sub) systems or partial systems of information designed for the work of the individual levels of business.

The basic problem of the formation and of the application of the examined information system is the requisite holism of the knowledge about the business situation, about the object of business (content knowledge), about the methods (knowledge of methodology), and about the values, which all provide their adequacy, as a dialectical system. 
The Virtual Organization

\section{References}

Allcorn, S. (1997). Parallel virtual organizations - managing and working in the virtual workplace. Administration \& Society, $29,4,412-439$.

Anderson, J., Narus, J. (1990). A Model of Distributor Firm and Manufacturer Firm Working Partnership. Journal of Strategic Management, 54, 42-58.

Anderson, J., Hakasson, M., Johnson, J. (1994). Dynamic business relationships within a business network context. Journal of Strategic Management, 58, 1-15.

Ashby, R. (1973). An Introduction to Cybernetics. London: Chapman in Hall.

Bakos, J. Y. (1991). A Strategic Analysis of Electronic Marketplaces. MIS Quarterly, 15, 3, 295-310.

Becker, J., Kugeler, M., Rosemann, N. (2000). Prozessmanagement. Heidelberg: Springer-Verlag.

Black, J., Edwards, S. (2000). Emergence of virtual or network organizations: Fad or feature. Journal of Organizational Change Management, 13, 6, 567-576.

Borghoff, U., Pareschi, R. (1998). Information Technology for Knowledge Management. Berlin: Springer-Velag.

Brittan, D. (1997). Business lessons from Darwin. MIT Reporter, 12.01, 12-13.

Checkland, P., Holwell, S. (1998). Information, Systems, and Information Systems. Sussex: John Wiley \& Sons.

Davidow, W. H., Malone, M. S. (1993). The Virtual Corporation. New York: Harper Business.

Dabic, M. (2000). The Development of Market Democracy Through the Use of Information Technology, Market Democracy in Croatia situation and Prospects Varaždin. 26 i 27 October, pp. 167-181.

Dess, G. G., Rasheed, A. M., McLaughlin, K. J., Priem, R. L. (1995). The new corporate architecture. Academy of Management Executive, 9, (3), 7-17.

Flood, R. (1999). Rethinking the Fifth Discipline: Learning with the Unknowable. London: Rootledge.

Fry, R., Stoner, C. (2000). Business: An Integrative Approach. Boston: McGraw Hill.

Gundlach, G., Achool, R., Mentzer, J. (1995). The structural commitment in exchange. Journal of Strategic Management, 59, (4), 78-82.

Gunton, T. (1998). Infrastructure: Building a Framework for Corporate Information Handling. New York: Prentice Hall.

Harrigan, K. (1988). Joint Ventures and Competitive Strategy. Strategic Management Journal, 9, 141-158.000

Harvey, M., Speier, C., Novicevic, M. (2000). An Innovative Global Management Staffing system: A Competency-Based Perspective. Human Resource Management Journal, Vol. 39 (3).

Harvey, M., Dabic, M. (2001). The Management of Strategic Global Relationship Knowledge: A Virtual Perspective. In: International Conference on Global Business \& Economic Development. Bratislava: November 2001.

Hill, C., Hitt, M., Hoskisson, R. (1992). Cooperative versus competitive structures in related and unrelated diversified firms. Organization Science, 3 (4), 501-521.

Ireland, R., Hitt, M. (1997). Performance Strategies for high Growth Entrepreneurial Firms. Frontiers of Entrepreneurship Research, 9-104.

Johansson, J. (1995). International alliances: Why now? Journal of Academy of Marketing Science, 23, (4), 301-304.

Kajzer, S., Mulej, M. (1999). Systemtheoretisch fundierte Ethik als Ueberlebungskonzept in turbulenten Zeiten der Innovativen Wirtschaft und Gesellschaft. In: Schwaninger, M. (Hrsg.), Ueberlebungskonzepte für turbulente Zeiten. Berlin: Humblot.

Laudon, K., Laudon, J. (1998). Management Information Systems: A Contemporary Perspective. New York: McMillan Publishing.

Lucey, T. (1998). Management Information Systems. London: Letts Company.

Modis, T. (1998): Conquering uncerainty: Understanding corporate cycles and positioning your company to survive the changing environment. New York: McGraw-Hill.

Merry, U. (1999). Nonlinear Organizational Dynamics. http://pw2.netcom.com/ nmerry/art2.htm 
Merry, U. (2000). Organizations versus natural systems. http://www.tresholds.com/journal/articles/(marryone.htmmerrytwo.htm), 08.12.2000.

Mulej, M., Kajzer, S. (1998). Ethics of Interdependence and the Law of Requisite Holism. In: Rebernik, M., Mulej, M. (eds.): STIQE '98. Proceedings of the 4th International Conference on Linking Systems Thinking, Innovation, Quality, Entrepreneurship and Environment. Maribor: Institute for Systems Research.

Mulej, M. (et al.) (2000). Basics of Systems Theory. Maribor: University of Maribor, Faculty of Economics and Business, International Program FEBA.

Oates, D. (1998). Outsourcing and the Virtual Organization. New York: Barron-s Business Success Guide.

Porter, M. (1985). Competitive Advantage. New York: Free Press.

Porter, M. (1990). Competitive Advantage of Nations. New York: Free Press.

Potocan, V. (1997). Synergy and integration processes in business. Management, Vol. 2 (2), pp. 13-24.

Potocan, V., Kajzer, S., Mulej, M. (1997). The Standardization of the Methodological Basis of Business Decision-making as a Contribution to the Revival of the Systems Theory. In: Problems of excavating cybernetics and systems. Systemica, Southsea Amsterdam, N. 1 - 6, pp. 259 - 268.

Potocan, V. (2001). Synergies in a virtual company. Journal for Management and Development. Vol. 2 (4), 45-60.

Rayport, J. F., Sviokla, J. J. (1995). Exploiting the virtual value chain. Harvard Business Review, November-December, 75-85.

Rebernik, M., Mulej, M. (2000). Requisite holism, isolating mechanisms and entrepreneurship. Kybernetes, Vol. 29, No. 9/10, pp. $1126-1140$.

Ring, P., Van De Ven, A. (1992). Structuring Cooperative Relationships Between. Organizations. Strategic Management Journal, 13, 531-544.

Schultheis, R., Sumner, M. (1998). Management Information System. Boston: McGraw Hill.

Snow, C., Miles, R., Coleman, H. (1992). Managing $21^{\text {st }}$ Century Network Organizations. Organizational Dynamics, 20, (3), 520.

Speier, C., Harvey, M., Palmer, J. (1998). Virtual Management of Global Marketing Relationships. Journal of World Business, Vol. 33 (3).

Varadarajin, R., Cunningham, M. (1995). Strategic alliances: A synthesis of conceptual foundations. Journal of Academy of Marketing Science, 23, (4), 282-296.

Williamson, O. (1991). Comparative economic organizations: The analysis of discrete structural alternatives. Administrative Service Quarterly, 36, 269-296. 